\title{
РАЗДЕЛЕНИЕ И КОЛИЧЕСТВЕННОЕ ОПРЕДЕЛЕНИЕ ХЛОРИСТОГО ГЕРАНИЛГЕКСАМЕТИЛЕНТЕТРАМИНА В СМЕСИ С ЕГО ГОМОЛОГАМИ
}

Хлористый геранилгексаметилентетрамин $\left[\mathrm{C}_{10} \mathrm{H}_{17} \cdot \mathrm{N}_{4} \mathrm{C}_{6} \mathrm{H}_{12}\right] \mathrm{Cl}$ и его гомологи с общей формулой $\left[\mathrm{H}\left(\mathrm{C}_{5} \mathrm{H}_{8}\right)_{n} \cdot \mathrm{N}_{4} \mathrm{C}_{6} \mathrm{H}_{12}\right] \mathrm{Cl}$ образуются при селективной реакции гексаметилентетрамина (уротропина - У) с первичными аллильными галогенопроизводными хлортеломеров изопрена и могут быть отделены от остальных изомерных галогенопроизводных в виде водного раствора четвертичных солей [ $\left.{ }^{1}\right]$. Хлористый геранилгексаметилентетрамин $\left(\mathrm{C}_{10} \cdot \mathrm{Y}\right)$ - основной компонент этой смеси.

В настоящей работе впервые разработана методика разделения $\mathrm{C}_{10} \cdot \mathrm{y}$ в смеси его гомологов при помощи электрофореза на бумаге. В качестве буферного раствора использовалась $0,5 \mathrm{M}$ уксусная кислота, в качестве хроматографической бумаги - бумага марки FN-11, $\mathrm{FN}-1$ и FN-12 (ГДР). Для количественного определения $\mathrm{C}_{10} \cdot \mathrm{V}$ и других разделенных компонентов применялась модифицированная методика колориметрического определения формальдегида и гексаметилентетрамина хромотроповой кислотой $\left[{ }^{2-4}\right]$. Разработанная методика позволяет контролировать состав промежуточных продуктов при получении синтетического цитраля $\left[{ }^{1}\right]$.

\section{Экспериментальная часть}

Характеристика исходных веществ:

Фракция 1,4-гидрохлорида изопрена $-\mathrm{C}_{5}$ Фракция монотерпеновых хлоридов $-\mathrm{C}_{10}$ Фракция сесквитерпеновых хлоридов $-\mathrm{C}_{15}$ Фракция политерпеновых хлоридов - $\mathrm{C}_{\text {п }}$

Гексаметилентетрамин Ацетон Уксусная кислота $d_{4}{ }^{20} \quad n_{D^{20}} \quad \mathrm{Cl}$ перв., $\%$

$\begin{array}{llr}0,9314 & 1,4492 & 32,0 \\ 0,9465 & 1,4802 & 10,5 \\ 0,9539 & 1,4890 & 6,5 \\ 0,9420 & 1,5080 & 2,6\end{array}$

ГОСТ 1381-73

Ty 6-09-35113-75

ГОСТ 18270

Синтез гомологов хлористых солей аллилгексаметилентетрамина осуществлен по методике, описанной в [5].

В синтезированных соединениях определялось содержание хлор-иона и хлора в виде соляной кислоты $\left[{ }^{6}\right]$. Полученные результаты даны в табл. 1.

Электропроводность водных растворов синтезированных соединений определялась при помощи кондуктометра MM 34-64 (табл. 11). Для разделения веществ использовался прибор электрофореза на бумаге фирмы «Carl Zeiss, Jena», который обеспечивает напряжение между электродами до 200 B. Колориметрические определения выпол- 
Результаты определения хлор-иона в синтезированных соединениях

\begin{tabular}{|c|c|c|c|}
\hline \multirow[b]{2}{*}{ - Синтезированные соединения } & \multirow{2}{*}{$\begin{array}{l}\text { Суммар- } \\
\text { ное ко- } \\
\text { личеств } \\
\text { хлор- } \\
\text { иона, \% }\end{array}$} & \multicolumn{2}{|c|}{$\begin{array}{c}\text { Количество связан- } \\
\text { ного хлора, } \%\end{array}$} \\
\hline & & $\begin{array}{c}\text { в соля- } \\
\text { ной кис- } \\
\text { лоте }\end{array}$ & $\begin{array}{l}\text { в четвер- } \\
\text { тичной } \\
\text { соли } \\
\text { аммония }\end{array}$ \\
\hline $\begin{array}{l}{\left[\mathrm{C}_{5} \mathrm{H}_{9} \cdot \mathrm{N}_{4} \mathrm{C}_{6} \mathrm{H}_{12}\right] \mathrm{Cl}\left(\mathrm{C}_{5} \cdot \mathrm{Y}\right)} \\
{\left[\mathrm{C}_{10} \mathrm{H}_{17} \cdot \mathrm{N}_{4} \mathrm{C}_{6} \mathrm{H}_{12}\right] \mathrm{Cl} \quad\left(\mathrm{C}_{10} \cdot \mathrm{Y}\right)} \\
{\left[\mathrm{C}_{15} \mathrm{H}_{25} \cdot \mathrm{N}_{4} \mathrm{C}_{6} \mathrm{H}_{12}\right] \mathrm{Cl} \quad\left(\mathrm{C}_{15} \cdot \mathrm{Y}\right)} \\
{\left[\mathrm{H}\left(\mathrm{C}_{5} \mathrm{H}_{8}\right)_{4-6} \cdot \mathrm{N}_{4} \mathrm{C}_{6} \mathrm{H}_{12}\right] \mathrm{Cl}\left(\mathrm{C}_{\mathrm{II}} \cdot \mathrm{y}\right)}\end{array}$ & $\begin{array}{r}14,2 \\
13,0 \\
10,8 \\
7,8\end{array}$ & $\begin{array}{l}0,8 \\
1,2 \\
1,5 \\
2,0\end{array}$ & $\begin{array}{r}13,4 \\
111,8 \\
9,3 \\
5,8\end{array}$ \\
\hline
\end{tabular}

таблица 2

Удельная $(x)$ и эквивалентная $(\lambda)$ электропроводности растворов исследуемых соединений

\begin{tabular}{|c|c|c|c|c|c|c|c|c|}
\hline \multirow{2}{*}{$\begin{array}{c}\text { Кон- } \\
\text { цент- } \\
\text { рация } \\
\text { раст- } \\
\text { воров, } \\
\text { 2-экв./л } \\
\end{array}$} & \multicolumn{4}{|c|}{$x, O_{M^{-1}} \cdot \mathrm{CM}^{-1}$} & \multicolumn{4}{|c|}{$\lambda, O_{M^{-1} \cdot 2-э \kappa в \cdot-1} \cdot{ }^{-1} M^{2}$} \\
\hline & $\mathrm{C}_{15} \cdot \mathrm{y}$ & $\mathrm{C}_{10} \cdot \mathrm{y}$ & $\mathrm{C}_{5} \cdot \mathrm{y}$ & $\mathrm{y}$ & $\mathrm{C}_{15} \cdot \mathrm{y}$ & $\mathrm{C}_{10} \cdot \mathrm{y}$ & $\mathrm{C}_{5} \cdot \mathrm{y}$ & $\mathrm{y}$ \\
\hline $\begin{array}{l}0,05 \\
0,02\end{array}$ & $\begin{array}{l}8,10 \cdot 10^{-3} \\
3,81 \cdot 10^{-3}\end{array}$ & $\begin{array}{l}6,07 \cdot 10^{-3} \\
2,50 \cdot 10^{-3}\end{array}$ & $\overline{-}$ & - & $\begin{array}{l}162 \\
191\end{array}$ & $\begin{array}{l}121 \\
125\end{array}$ & - & - \\
\hline 0,01 & $1,95 \cdot 10^{-3}$ & $1,27 \cdot 10^{-3}$ & $1,01 \cdot 10^{-3}$ & $1,09 \cdot 10^{-5}$ & 195 & 127 & 101 & 1,09 \\
\hline 0,001 & $1,76 \cdot 10^{-4}$ & $1,47 \cdot 10^{-4}$ & - & - & 176 & 147 & - & - \\
\hline
\end{tabular}

нялись на фотоколориметре ФЕК-56М с использованием зеленого светофильтра (кюветы с длиной проходящего света 30,17 мм).

Процесс электрофоретического разделения осуществлялся в закрытой камере на лентах хроматографической бумаги размером $40 \times 300$ м.м, предварительно смоченных буферным раствором и слегка подсушенных между листами фильтровальной бумаги. После стабилизации режима в камере при максимальном напряжении в течение 1 ч растворы исследуемых соединений и их смеси наносились на ленты бумаги полосками бумаги 1-2 Х 32 мм через щели в крышке камеры. Измерение количества раствора на полосках проводилось микробюреткой (точность деления 1 мкл). После окончания эксперимента электрофореграммы слегка подсушивались, разделенные зоны проявлялись парами йода и экстрагировались дистиллированной водой.

\section{Результаты экспериментов и их обсуждение}

1. Разделение смеси гомологов хлористых солей аллилгексаметилентетрамина. В табл. 2 приведены полученные экспериментальным путем удельные $(\varkappa)$ и эквивалентные $(\lambda)$ электропроводности растворов в зависимости от концентрации исследуемых веществ [ $\left.{ }^{7}\right]$. Наблюдаемая разница в эквивалентных электропроводностях в пределе концентрации $0,01-0,02$ н. растворов позволила сделать предположение о наличии разницы и в электрофоретических подвижностях $\left[{ }^{8}\right]$.

С целью выбора оптимальных условий разделения электрофоретические подвижноети зон исследуемых соединений определялись в зависимости от условий разделения. Для опытов было взято 35 мке смеси. Электрофоретическая подвижность отдельных соединений оценивалась по расстоянию от линии старта до переднего края зоны вещества (табл. 3). 
таблица 3

Электрофоретические подвижности зон исследуемых соединений и разделение их смесей

\begin{tabular}{|c|c|c|c|c|c|c|c|c|c|}
\hline \multirow{2}{*}{$\begin{array}{c}\text { Сорт } \\
\text { бумаги }\end{array}$} & \multirow{2}{*}{$\begin{array}{c}\text { Гради- } \\
\text { ент по- } \\
\text { тен- } \\
\text { циала, } \\
B \cdot c \text { - }^{-1}\end{array}$} & \multirow{2}{*}{$\begin{array}{l}\text { Время } \\
\text { элект- } \\
\text { рофо- } \\
\text { реза, } \iota\end{array}$} & \multicolumn{4}{|c|}{$\begin{array}{c}\text { Электрофоретическая } \\
\text { подвижность, мм }\end{array}$} & \multicolumn{3}{|c|}{$\begin{array}{c}\text { Среднее расстояние между } \\
\text { зонами разделенных ком- } \\
\text { понентов, мм }\end{array}$} \\
\hline & & & $\mathrm{C}_{5} \cdot \mathrm{y}$ & $\mathrm{C}_{10} \cdot \mathrm{y}$ & $\mathrm{C}_{15} \cdot \mathrm{y}$ & $\mathrm{C}_{\mathrm{nI}} \cdot \mathrm{y}$ & $\begin{array}{l}\mathrm{C}_{5} \cdot \mathrm{y}-\mathrm{C}_{10} \cdot \mathrm{y} \\
-\mathrm{C}^{2}\end{array}$ & ${ }_{-C_{15}}^{\mathrm{C}_{10} \cdot \mathrm{y}}$ & $\frac{\mathrm{C}_{15} \cdot \mathrm{y}-}{-\mathrm{C}_{\mathrm{II}} \cdot \mathrm{y}}$ \\
\hline
\end{tabular}

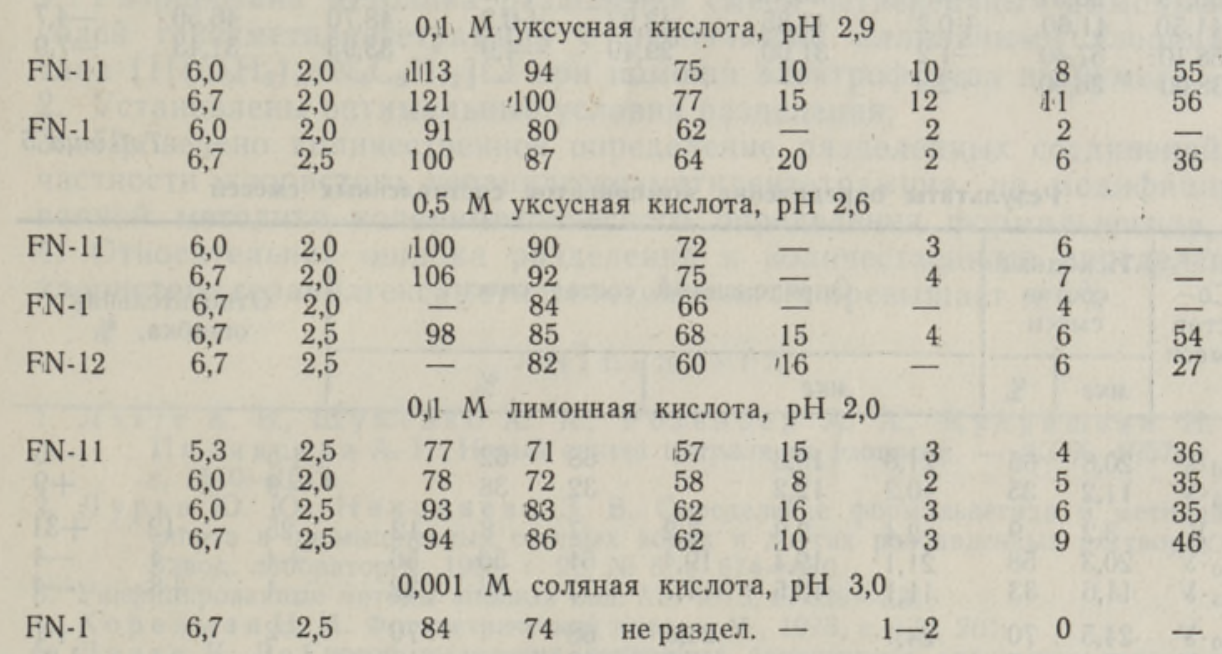

Оптимальными условиями оказались следующие: 0,5 M уксусная кислота на хроматографической бумаге марки FN-11, FN-1 и FN-12 при градиенте потенциала $6,7 \mathrm{~B} \cdot \mathrm{cM^{-1 }}$ и продолжительности электрофореза, в зависимости от марки бумаги, - от 2 до 2,5 ч; количество смеси, наиболее способной к разделению, - 30-35 мкг, нанесенной на ленты бумаги (0,02 M ра́створ) при помощи полосок бумаги $2 \times 32$ мм.

Хорошие результаты разделения достигались и при использовании 0,1 М уксусной кислоты и длительности электрофореза 2 , но компактность и разграниченность зон все же лучше при использовании 0,5 M уксусной кислоты. Удовлетворительными были результаты и при применении 0,1 М лимонной кислоты (табл. 3 ).

2. Количественное определение разделенных компонентов. Исследуемые соединения представляют собой комплексные соли аллильных первичных хлоридов с гексаметилентетрамином, разлагающиеся в условиях колориметрического определения с выделением соответствующего количества формальдегида, которое возможно установить методом [ $\left.{ }^{3}\right]$.

Для колориметрического определения использовался «хч» гексаметилентетрамин, из которого была приготовлена серия стандартных растворов, содержащих 1,4-20,0 мка вещества. В дальнейшем определение проводилось по методике, описанной в [ [3]. Результаты представлены на рисунке, являющемся графиком для последующего определения.

Для уточнения условий колориметрического определения исследуемых соединений были приготовлены растворы определенной концентрации отдельных соединений. Выяснилось, что для полного разложения комплексных соединений необходимо увеличить время нагревания в водяной бане до 1 ч. В табл. 4 приведены взятые количества (по рас- 
Таблица 4

Результаты колориметрического определения

\begin{tabular}{|c|c|c|c|c|c|c|c|c|}
\hline \multicolumn{2}{|c|}{$\mathrm{C}_{15} \cdot \mathrm{Y}$, мкг } & \multirow{2}{*}{$\begin{array}{c}\text { Отно- } \\
\text { ситель- } \\
\text { ная } \\
\text { ошибка, } \\
\%\end{array}$} & \multicolumn{2}{|c|}{$\mathrm{C}_{10} \cdot \mathrm{Y}$, мкг } & \multirow{2}{*}{$\begin{array}{c}\text { Отно- } \\
\text { ситель- } \\
\text { ная } \\
\text { ошибка, } \\
\%\end{array}$} & \multicolumn{2}{|c|}{$\mathrm{C}_{5} \cdot \mathrm{y}$, мка } & \multirow{2}{*}{$\begin{array}{c}\text { Отно- } \\
\text { ситель- } \\
\text { ная } \\
\text { ошибка, } \\
\%\end{array}$} \\
\hline Взятый & $\begin{array}{l}\text { Полу- } \\
\text { ченный }\end{array}$ & & Взятый & $\begin{array}{l}\text { Полу- } \\
\text { ченный }\end{array}$ & & Взятый & $\begin{array}{l}\text { Полу- } \\
\text { ченный }\end{array}$ & \\
\hline $\begin{array}{l}55,79 \\
41,50 \\
58,10 \\
38,00\end{array}$ & $\begin{array}{l}53,31 \\
41,60 \\
57,40 \\
36,90\end{array}$ & $\begin{array}{l}-4,4 \\
+0,2 \\
-1,2 \\
-2,9\end{array}$ & $\begin{array}{c}43,40 \\
43,85 \\
31,00 \\
-\end{array}$ & $\begin{array}{c}43,90 \\
43,93 \\
29,49 \\
-\end{array}$ & $\begin{array}{r}+1,2 \\
+0,2 \\
-4,9 \\
-\end{array}$ & $\begin{array}{l}24,43 \\
48,70 \\
33,93 \\
-\end{array}$ & $\begin{array}{c}21,23 \\
46,50 \\
31,43 \\
-\end{array}$ & $\begin{array}{r}-13,1 \\
-4,7 \\
-7,9 \\
-\end{array}$ \\
\hline
\end{tabular}

Таблица 5

Результаты определения компонентов составленных смесей

\begin{tabular}{|c|c|c|c|c|c|c|c|c|c|c|c|}
\hline \multirow{2}{*}{$\begin{array}{l}\text { Co- } \\
\text { став } \\
\text { смеси }\end{array}$} & \multicolumn{2}{|c|}{$\begin{array}{c}\text { Исходный } \\
\text { состав } \\
\text { смеси }\end{array}$} & \multicolumn{6}{|c|}{ Определенный состав смеси } & \multirow{2}{*}{\multicolumn{3}{|c|}{$\begin{array}{c}\text { Относительная } \\
\text { ошибка, \% }\end{array}$}} \\
\hline & мке & $\%$ & & мке & & & $\%$ & & & & \\
\hline $\begin{array}{l}\mathrm{C}_{10} \cdot \mathrm{y} \\
\mathrm{C}_{15} \cdot \mathrm{y}\end{array}$ & $\begin{array}{l}20,8 \\
11,2\end{array}$ & $\begin{array}{l}65 \\
35\end{array}$ & $\begin{array}{l}21,8 \\
10,2\end{array}$ & $\begin{array}{l}19,8 \\
12,2\end{array}$ & & $\begin{array}{l}68 \\
32\end{array}$ & $\begin{array}{l}62 \\
38\end{array}$ & & $\begin{array}{l}+5 \\
-9\end{array}$ & & $\begin{array}{l}-5 \\
+9\end{array}$ \\
\hline $\begin{array}{l}\mathrm{C}_{5} \cdot \mathrm{y} \\
\mathrm{C}_{10} \cdot \mathrm{y} \\
\mathrm{C}_{15} \cdot \mathrm{y}\end{array}$ & $\begin{array}{r}3,2 \\
20,3 \\
11,6\end{array}$ & $\begin{array}{r}9 \\
58 \\
33\end{array}$ & $\begin{array}{r}2,4 \\
21,1 \\
11,1\end{array}$ & $\begin{array}{r}2,8 \\
19,4 \\
12,5\end{array}$ & $\begin{array}{r}4,2 \\
19,4 \\
11,1\end{array}$ & $\begin{array}{r}7 \\
61 \\
32\end{array}$ & $\begin{array}{r}8 \\
56 \\
36\end{array}$ & $\begin{array}{l}12 \\
56 \\
32\end{array}$ & $\begin{array}{r}-25 \\
+4 \\
-4\end{array}$ & $\begin{array}{l}-12 \\
-4 \\
+8\end{array}$ & $\begin{array}{r}+31 \\
-4 \\
-4\end{array}$ \\
\hline $\begin{array}{l}C_{10} \cdot y \\
C_{15} \cdot y \\
C_{n} \cdot y\end{array}$ & $\begin{array}{r}24,5 \\
5,2 \\
5,2\end{array}$ & $\begin{array}{l}70 \\
15 \\
15\end{array}$ & $\begin{array}{r}24,1 \\
6,3 \\
5,1\end{array}$ & & $\begin{array}{r}24,8 \\
6,6 \\
4,0\end{array}$ & $\begin{array}{l}68 \\
18 \\
14\end{array}$ & & $\begin{array}{l}70 \\
18 \\
14\end{array}$ & $\begin{array}{r}-2 \\
+21 \\
-2\end{array}$ & & $\begin{array}{r}+1 \\
+27 \\
-23\end{array}$ \\
\hline $\begin{array}{l}C_{5} \cdot y \\
C_{10} \cdot y \\
C_{15} \cdot y \\
C_{n} \cdot y\end{array}$ & $\begin{array}{r}1,8 \\
27,4 \\
5,4 \\
1,4\end{array}$ & $\begin{array}{r}5 \\
76 \\
15 \\
4\end{array}$ & $\begin{array}{r}1,4 \\
25,9 \\
6,2 \\
1,2\end{array}$ & & $\begin{array}{r}1,5 \\
26,0 \\
5,9 \\
1,0\end{array}$ & $\begin{array}{r}4 \\
74 \\
18 \\
4\end{array}$ & & $\begin{array}{r}4 \\
76 \\
17 \\
3\end{array}$ & $\begin{array}{r}-22 \\
-5 \\
+15 \\
-14\end{array}$ & & $\begin{array}{r}-17 \\
-5 \\
+9 \\
-28\end{array}$ \\
\hline
\end{tabular}

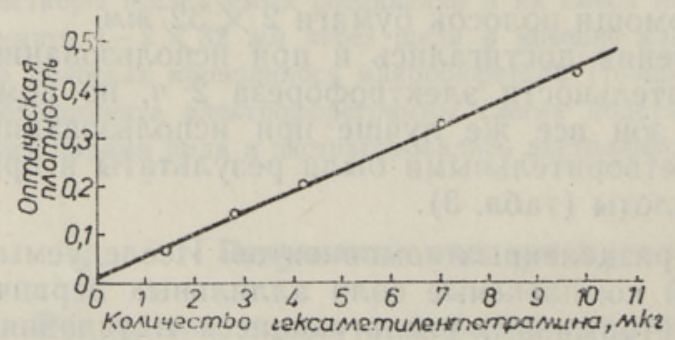

Зависимость между оптической плотностью и количеством гексаметилентетрамина в растворе.

чету содержания хлор-иона) и полученные данные колориметрического определения, а также относительная ошибка.

Для определения концентрации раздсленных компонентов соответствующие зоны экстрагировались из электрофореграмм дистиллированной водой порциями по $1-2$ мл. Водяная вытяжка и промывные воды отфильтровывались и собирались в калиброванные пробирки (объемом 20 мл). Суммарное количество фильтрата не должно превышать 7 -8 мл. Для проверки полноты экстрагирования его повторяли, собирая фильтрат в другую пробирку. Проверка показала, что вторичное экстрагирование нужно лишь в случае содержания на электрофореграммax $\mathrm{C}_{5} \cdot \mathrm{У}$ выше 18 мкг, $\mathrm{C}_{10} \cdot \mathrm{У}$ выше 24 мкг и $\mathrm{C}_{15} \cdot \mathrm{y}$ выше 28 мкг.

К полученным фильтратам прибавлялось 0,5 мл $2 \%$-ного свежеприготовленного раствора хромотроповой кислоты и 5 мл концентрированной серной кислоты. Содержимое пробирок перемешивалось стеклянной палочкой и нагревалось на кипящей водяной бане в течение 1 ч. 
Параллельно ставились холостой опыт и опыт с известным количеством гексаметилентетрамина. По полученным оптическим плотностям вычислялись количества исследуемых соединений в смеси (табл. 5).

Относительная ошибка определения содержания хлористого геранилгексаметилентетрамина в смеси его гомологов не превышает $\pm 5 \%$ (табл. 5).

\section{Выводы}

1. Разработана методика разделения смеси четвертичных аммониевых солей гексаметилентетрамина с первичными аллильными хлоридами типа $\left[\mathrm{H}\left(\mathrm{C}_{5} \mathrm{H}_{8}\right)_{n} \cdot \mathrm{N}_{4} \mathrm{C}_{6} \mathrm{H}_{12}\right] \mathrm{Cl}$ при помощи электрофореза на бумаге.

2. Установлены оптимальные условия разделения.

3. Проведено количественное определение разделенных соединений, в частности хлористого геранилгексаметилентетрамина, по модифицированной методике колориметрического определения формальдегида.

4. Относительная ошибка разделения и количественного определения хлористого геранилгексаметилентетрамина не превышает $\pm 5 \%$.

\section{Л ИТЕ РА Т У РА}

1. Л ээтс К. В., Шумейко А. К., Розеноер А. А., Кудряшева Н. В., Пи л я в ск а я А. И. Новый синтез цитраля из изопрена. - ЖОХ, 1957, т. 27, c. $1510-1512$.

2. Лурье Ю. Ю., Николаева 3. В. Определение формальдегида и метилового спирта в промышленных сточных водах и других разбавленных растворах. Завод. лаборатория, 1954 , т. 20 , № 6, с. $674-680$.

3. Унифицированные методы анализа вод. М., 1973, с. $329-331$.

4. Корен м а н И. М. Фотометрический анализ. М., 1975, с. 179, 201.

5. Лээті К. В. Способ выделения первичных замещенных аллильных галоидопроизводных из смесей с изомерными соединениями. Авт. свид. № 128860 . Бюл. изобретений, 1960, № 111 .

6. К удр я в це в И., Л ээ тс К., Т а л и М. Получение цитраля и иононов из синтетических геранилхлоридов. - Изв. АН ЭССР. Хим. Геол., 1968, т. 17, № 4, c. $361-367$.

7. К ре ш ков А. П. Основы аналитической химин. 3. М., 1970, с. 72.

8. Л еде рер М. Введение в электрофорез на бумаге и родственные методы. М., 1956.

Ннститут химии

Академии наук Эстонской ССР

\section{Поступила в редакцию} 23/III 1978

Hilja RAUDOJA, K. LAATS

\section{GERANOULHEKSAMETOLEENTETRAMIINKLORIIDI LAHUTAMINE TEMA HOMOLOOGIDE SEGUST JA KVANTITATIIVNE MÄÄRAMINE}

On esitatud kvaternaarsete ammooniumsoolade segu (sünteetilise tsitraali tootmise vaheproduktid, üldvalem $\left[\mathrm{H}\left(\mathrm{C}_{5} \mathrm{H}_{8}\right)_{n} \cdot \mathrm{N}_{4} \mathrm{C}_{6} \mathrm{H}_{12}\right] \mathrm{Cl}$ ) paberelektroforeetilise lahutamise meetod ning lahutatud komponentide kolorimeetrilise määramise tulemused. Peamise komponendi, geranüülheksametüleentetramiinkloriidi määramise suhteline viga ei ületa $\pm 5 \%$.

Hilja RAUDOJA, K. LAATS

\section{SEPARATION OF GERANYLHEXAMETHYLENETETRAMINE CHLORIDE AND ITS HOMOLOGUES AND DETERMINATION OF THE SEPARATED PRODUCTS}

A new separation and determination method of geranylhexamethylenetetramine chloride in the mixture of its homologues is presented. Separation was carried out by paper electrophoresis. Determination of the separated products was carried out colorimetrically. 